\title{
Revalorizando a natureza a Partir de VitTorio Hösle e Friedrich VON HARDENBERG (NOVALIS)
}

\author{
[Revaluing nature Based in VitTorio Hösle ANd Friedrich VOn Novalis (Novalis)]
}

\author{
Gabriel Almeida Assumpção * \\ Universidade Federal de Mnas Gerais, Brasil \\ Universidade Federal de Ouro Preto, Brasil
}

Resumo: Buscamos apresentar Friedrich von Hardenberg (Novalis) (1772-1801) como um percussor do pensamento ecológico, tendo em mente a valorização da natureza em sua filosofia, resultado de uma busca constante de superar o dualismo de Fichte por meio da poesia; do estudo das ciências naturais e do estudo de Plotino. Observamos que Novalis tenta, com êxito parcial, modificar sua filosofia de um idealismo subjetivo nos moldes de Fichte rumo ao sincriticismo (síntese de idealismo e realismo), reconhecendo importância tanto da natureza quanto da consciência humana. Esse tipo de pensamento, análogo ao que Vittorio Hösle (1960-) denomina "idealismo objetivo" em sua Filosofia da crise ecológica: conferências moscovitas (1991), é bem favorável à ecologia, reconhecendo o ser humano como parte da natureza, e não como algo separado dela. Embora o filósofo ítalo-germânico observe essa postura filosófica em Schelling e Hegel, acrescentamos Novalis como um representante dessa forma de se fazer filosofia.

Palavras-Chave: dualismo; ecologia; Hösle; natureza; Novalis; sincriticismo
AbSTRACT: We aim to present Friedrich von Hardenberg (Novalis) (1772-1801) as a precursor of ecological thought, observing how he values nature in his thought, as a result of a constant attempt to overcome Fichtean dualism by means of poetry, through the study of natural sciences and also by means of the study of Plotinus' philosophy. We observe that Novalis tries, with partial success, to modify his Philosophy, evolving from a subjective idealism in the Fichtean fashion towards a syncriticism (a synthesis between idealism and realism), recognizing both nature and human consciousness's importance. This kind of thought, analog to the "objective idealism" of Vittorio Hösle (1960-) in his Philosophy of Ecological Crisis: Muscovite Conferences (1991) is more compatible with ecology, recognizing human being as part of nature, not only as something apart from it. Although the German-Italian philosopher recognizes Schelling and Hegel as endowed with such attitude, we add Novalis as a representative of this way of doing philosophy.

KeYwords: dualism; ecology; Hösle; nature; Novalis; syncriticism

\section{Dedico esse artigo a Bruno Almeida Guimarães}

\section{INTRODUÇÃo} Campo da filosofia da natureza perdeu, no século XX, muito espaço para a maior capacidade da racionalidade cientifica de explicar e prever eventos no mundo * Bolsista de Pós-Doutorado Júnior - CNPq: Conselho Nacional de Desenvolvimento Científico e Tecnológico. Processo número 162879/2020-2. Traduziu as seguintes obras filosóficas do alemão para Português brasileiro: 'Dedução geral do processo dinâmico' (1800), de F. W. J. Schelling; 'Filosofia da crise ecológica: conferências moscovitas' (1991), de Vittorio Hösle. E-mail: gabrielchou@gmail.com 
físico, enquanto a filosofia da natureza nem sempre obteve esse êxito. Entretanto, tendências atuais mostram a importância de uma reabilitação da filosofia da natureza, tendo em mente a crise ecológica e diversos problemas éticos e políticos a ela relacionados, como enfatizam Hösle (1991) e Van der Val (2017). Há, também, abordagens que articulam estética e filosofia da natureza, como no caso de Martin Seel (1996), cuja obra convida a pensar ecologicamente a beleza natural, ou a de AUTOR (2017), que investigou o elo entre concepções dinâmicas de natureza e o pensamento estético de Wassily Kandinsky e Paul Klee.

No caso deste artigo, abordaremos o ponto de vista de Vittorio Hösle (1960-), autor da Filosofia da crise ecológica: conferências moscovitas (1991), conciliando sua visão com a do poeta e filósofo romântico, Friedrich von Hardenberg, vulgo Novalis (1772-1801). Embora Hösle não seja um intérprete de Novalis, consideramos que a maneira como este exibe grande valorização da natureza em sua obra permite contribuições para uma filosofia da natureza de cunho ecológico.

As obras de Hösle são sobre temas diversos, desde o diálogo filosófico até os filmes de Woody Allen e Éric Rohmer, passando por ética, política e metafísica. Embora seja um autor traduzido para muitos idiomas, ainda há poucos estudos sobre sua obra, mas já podemos notar trabalhos como o de Souza (2006), que vincula o pensamento de Hösle com o de Joseph Maréchal, no que diz respeito a uma fundamentação última do conhecimento, e uma crítica de Albert (1989) quanto a essa possibilidade em Hösle. Heldt (2016) confronta, de um lado, o arrazoado de Hegel sobre a relação entre lógica e filosofia da realidade com, de outro lado, a interpretação de Hösle sobre o filósofo do idealismo alemão. Oliveira (2016) nos mostra a validade de se pensar a filosofia da natureza hoje, tendo em mente Hegel, Dieter Wandschneider e Hösle. Especificamente sobre a filosofia da crise ecológica, o primeiro artigo encontrado foi de Muller (1996), que apresenta os argumentos centrais da obra de Hösle. Há também um estudo introdutório de AUTOR; CO-AUTOR (2019), que insere a Filosofia da crise ecológica no contexto do pensamento de Hösle, indicando problemas atuais no Brasil (como o desmatamento predatório da Floresta Amazônica). Merece destaque o estudo de MATIJEVIĆ (2015), no qual se defende que, apesar de muitos anos terem se passado desde 1989 (ano em que as conferências de Hösle foram ministradas, tendo sido publicadas dois anos depois), grande parte das análise de Hösle sobre a crise ecológica são atuais e as soluções por ele propostas (por exemplo, impostos ambientais e uma revisão do conceito de propriedade privada) são ainda relevantes.

Sobre Novalis, ainda há muito a se pesquisar, tendo o autor sido mais estudado na teoria literária, devido às grandes contribuições dele e de Friedrich Schlegel para o próprio surgimento do campo de teoria da literatura, como nota Schell (2010). Muitas vezes, Novalis foi interpretado a partir de uma ótica fichteana (FRANK, 1989; SCHELL, 2010; SELIGMANN-SILVA, 2006), sendo ele visto como um pensador pouco original, cuja relevância filosófica teria sido introduzir Fichte ao romantismo alemão. Houve, recentemente, tentativa de filiar Novalis ao projeto crítico kantiano (CORÔA, 2019), o que só é viável quando não se considera sua filosofia da natureza e a tendência mística de Novalis, com isso perdendo grande parte do que faz dele um pensador original.

Nossa linha interpretativa, no que tange a von Hardenberg, ou Novalis, é mais próxima do clássico Friedell (1904), cuja obra, embora já antiga, traz uma interpretação bem coesa do filósofo romântico, cuja filosofia antecipa muitas teses importantes do idealismo alemão, como a identidade entre sujeito e objeto, a primazia da arte sobre a filosofia (tal como no jovem Schelling), e uma filosofia da natureza norteada pela concepção da natureza como dotada de inteligência própria. Outros intérpretes dos quais 
nos aproximamos são Beiser (2002, 2003), Nassar (2014) e Uerlings (1991), que notam a importância de Plotino na trajetória filosófica de Novalis, e também em seu parcial distanciamento de teses fichteanas, culminando em uma valorização da natureza como dotada de inteligência e de vida própria. Nossa interpretação também é devedora da de Losso (2020), na medida em que reconhece a importância do tratamento novalisiano da natureza e do misticismo na obra do filósofo-poeta, porém temos foco metodológico nos fragmentos, e não na obra literária, como fez Losso.

Diferenciais de nossa pesquisa em relação às supracitadas consistem (a) na articulação com o pensamento ecológico de Hösle, e (b) em acrescentar Novalis à interpretação daquele, segundo a qual filósofos que reconhecem tanto a importância da natureza quanto da consciência tendem a ser mais compatíveis com a ecologia. Hans Jonas é a inspiração principal de Hösle, no que tange ao problema ecológico, mas não falaremos diretamente sobre ele para que o artigo não fique demasiadamente polifônico e, também, devido ao fato de que Jonas, felizmente, já é um pensador significativamente mais estudado e traduzido no Brasil, sendo mais oportuno dar vez a filósofos menos pesquisados.

\section{NOVALIS E A VALORIZAÇÃO ROMÂNTICA DA NATUREZA}

A filosofia de Novalis não apresenta um projeto uniforme e claro, sendo sua obra marcada por posturas divergentes, mudanças bruscas de tema e tendência antissistemática. A própria escrita em fragmentos filosóficos contribui para que seu pensamento se mostre multifacetado, dificultando sua apreensão, porém com ganhos para quem se dispõe a buscar linha centrais de pensamento ao longo dos mais de três mil fragmentos do autor, a maioria dos quais é de caráter póstumo, e alguns dos quais foram publicados na revista romântica Athäneum.

Uma das intuições centrais de von Hardenberg é a inteligência da natureza (III, 1266, 153s), capaz de aplicar a matemática a si mesma e às suas formas: "A natureza adiciona, subtrai, multiplica, potencia, etc. incessantemente. As ciências matemáticas aplicadas nos indicam a natureza como uma matemática"1 (III, 1268, 155). Outra intuição recorrente é a a superioridade da poesia diante dos outros saberes, porém em forte interrelação com a filosofia: "A poesia é o autêntico absolutamente real. Esse é o cerne de minha filosofia. Quanto mais poético, mais verdadeiro"2 (III, 1247, 141). Podemos destacar, ainda, o papel elevado da matemática (III, 1084, 100) (III, 1229, 135). Dessas intuições, a que mais nos interessa é a primeira, devido ao nosso foco neste artigo.

A valorização da natureza e da ciência natural em Novalis é resultado de múltiplas influências em sua vida: seu estudo das ciências naturais, seu trabalho como inspetor em uma mina de sal, a leitura de Leibniz, Schelling ${ }^{3}$ e Plotino, e o ingresso, em 1797, na academia mineralógica de Freiberg, na qual pôde assistir a muitas aulas (NASSAR, 2014, p. 52). O resultado desse conjunto de influências, somado à originalidade de Novalis, é uma filosofia da natureza que resgata ideias dos antigos e tenta repensá-los na época moderna. Recupera-se a ideia de alma do mundo, pensando o mundo como um grande organismo (III, 891, 45s; III, 1229, 135). A natureza é pensada como algo dotado de inteligência própria, e o pesquisador da natureza aprende a dialogar com ela, tornando-se uma espécie de porta voz da mesma, um profeta da natureza (FRIDELL, 1904, p. 50). A concepção antiga de cada organismo como um microcosmos também é adotada por Novalis também, algo tipico da tradição neoplatônica (III, 1091, 101; III, 1256, 151; IV, 1962, 28s.). 
A partir da noção de que cada organismo - no caso específico do ser humano, cada indivíduo - é uma imagem do cosmos, von Hardenberg desenvolve uma concepção mística de natureza ao introduzir a magia em seu pensamento, falando explicitamente do "idealismo mágico". O idealismo mágico de Novalis se fundamenta em uma ideia de comunhão entre ser humano e natureza, aquele integrando esta, podendo nela interferir, chegando a modificar a realidade com o poder da magia. A natureza se torna uma extensão dos órgãos do ser humano, capaz de decifrar a linguagem da natureza e de transformá-la (BEISER, 2002, p. 431). O poeta, com seu acesso intuitivo à realidade, é mais que um artista, tornando-se um feiticeiro, profeta e mago (III, 1062, 97), tão poderoso quanto as estrelas (III, 1455, 204). Nas palavras de von Hardenberg: "Tudo é feitiçaria, ou nada. Conformidade da magia à razão"4 (III, 1286, 161). O idealismo mágico não seria um irracionalismo, mas um desdobramento da própria razão intuitiva.

Essa concepção de magia não seria aceita por Hösle, que considera a via mística pouco frutífera para se preservar a natureza (HÖSLE, 1991, p. 41).

E importante salientar que a concepção da natureza como um grande organismo, dotado de inteligência, cuja linguagem compete ao filósofo, ao poeta e ao cientista aprender, não é a única concepção de natureza presente em Novalis: nos Estudos sobre Fichte (1794-1796) e em várias outras passagens de sua obra, ele se mostra defensor de um radical dualismo entre Deus e mundo, ser humano e natureza, bem na linha de Fichte nos anos de Jena. Ele chega a defender uma moralização da natureza, tornando-a permeável à moralidade, e isso se reflete na busca pelo transcendente e mesmo pela morte em alguns de seus fragmentos (II, 209, 98; II, 109, 44; III, 1404, 196; IV, 2083, 55). O mundo físico, inclusive, é hostil ao indivíduo e à permanência: "A natureza é inimiga de posses eternas" ${ }^{\text {"II, }}$ 13, 12). O pensamento de von Hardenberg, como dito acima, é multifacetado, sendo que ele mostra tendências dualistas paralelamente à sua filosofia da natureza de intenção monista.

Novalis defende que a filosofia mais elaborada é o sincriticismo, uma síntese entre idealismo e realismo, evitando os extremos de ambas posturas. O filósofo sincrítico consegue reconhecer a importância da consciência, tal como fez Fichte, mas também reconhece a grandeza do mundo natural, como fez Espinosa. Com essa opção filosófica, o sincriticismo supera a dualidade não só entre natureza e espírito, corpo e mente, mundo e Deus, mas também na própria filosofia (IV, 1952, 23; IV, 2300, 133). O idealismo crítico é ou criticismo poético, ou criticismo moral (Kant, Fichte). O filósofo autêntico possui um método sintético, combinando a priori com a posteriori, fortalecendo e expandindo ambos procedimentos (IV, 2104, 65):

Idealização do realismo e realização do idealismo conduzem à verdade. Um trabalha para o outro e, portanto, indiretamente para si mesmo. O idealista deve, para trabalhar diretamente em prol do idealismo, buscar provar o realismo e viceversa. A prova do realismo é do idealismo, e vice-versa ${ }^{6}$ (IV, 2303, 134).

O sincriticismo, como síntese entre idealismo e realismo, é bem compativel com o que Vittorio Hösle chama idealismo objetivo, uma terminologia utilizada por Wilhelm Dilthey e Karl-Otto Apel. De acordo com o idealismo objetivo, tal como interpretado por Hösle (1998, pp. 18-19), é possível um conhecimento do mundo físico e social e de suas leis, mas esse conhecimento não depende apenas da consciência humana, a qual, por sua vez, encontra uma correspondência - finita e limitada - com uma consciência superior, de caráter divino. Esse tipo de filosofia estaria presente na tradição platônica, na maior parte dos filósofos medievais, e em mentes como Leibniz, Schelling e Hegel. O idealismo objetivo é uma síntese entre realismo e idealismo subjetivo (um tipo de filosofia semelhante à de Kant e de Fichte nos anos de Jena, segundo as quais o 
conhecimento depende da consciência humana e não permite acesso ao real).

A filosofia da Novalis, como notamos pelo estudo de seus fragmentos, apresenta uma tendência idealista subjetiva, dualista, e uma tendência idealista objetiva, por ele chamada "sincriticismo". Segundo Hösle (1991, p. 56), filósofos que se dedicaram mais a pensadores antigos possuiam uma tendência a desenvolver uma filosofia idealista objetiva, na qual a natureza era mais respeitada, citando como exemplo Leibniz, Schelling e Hegel. Podemos acrescentar Novalis a esse grupo, e pensar sobre como integrar ecologia e idealismo objetivo.

\section{COMo Novalis PODE AUXILIAR A FILOSOFIA DA CRISE ECOLÓGICA.}

Segundo Hösle, a crise ecológica que já se nota no século XX pode ser objeto de várias ciências, como a sociologia, a biologia, a economia, entre outras, mas isso não exclui a filosofia, a qual não deve ser indiferente aos rumos da humanidade. Prova disso é que Platão, Aristóteles e Fichte refletiram tanto sobre metafísica quanto sobre os problemas concretos de sua época (HÖSLE, 1991, pp. 14-15). O ser humano é portador de algo que o transcende, a lei moral, e cabe a ele refletir sobre quais caminhos está tomando, sendo responsável por seu destino. A filosofia da crise ecológica seria, nesse sentido, compatível com a filosofia da história. Evidentemente, essa filosofia não pode ser apenas teórica, mas possui também um componente prático ${ }^{7}-$ sobre o qual não versaremos nesse artigo, dado a ênfase ser em uma inserção de Novalis no pensamento ecológico, e o fato de isso já ter sido abordado em outros estudos relevantes (AUTOR, CO-AUTOR, 2019; MATIJEVIĆ, 2015; MULLER, 1996).

O filósofo ítalo-germânico enfatiza a importância de uma filosofia da natureza compatível com a grandeza da ciência natural moderna, mas isso só será possível quando houver maior abertura a um espírito interdisciplinar (HÖSLE, 1991, p. 46). No entanto, ele se esforça e sugere cinco conceitos de natureza, a partir dos quais a relação entre humano e natureza foi pensada ao longo da história. Há o conceito de natureza presente em culturas arcaicas, segundo o qual o ser humano é parte do grande organismo natureza, algo divino e vivo. A concepção de alma do mundo supracitada remete a essa concepção. Em seguida, há a concepção das sociedades agrícolas, em que já existe certa instrumentalização da natureza, surgindo já a astronomia. No mundo grego, surge a razão demonstrativa, e o uso da matemática para se investigar a natureza. Em seguida, há o excesso de explicações teleológicas na Idade Média, cuja grande contribuição foi a ideia de infinito, tendo sido Nicolau de Cusa peça-chave na transição rumo a um novo ideal científico, dependente do cristianismo. Finalmente, há o conceito da ciência moderna, que amplia a matematização do mundo e rompe com as explicações teleológicas sobre a natureza ${ }^{8}$ (HÖSLE, 1991, pp. 49-51).

Encontramos, curiosamente, todas essas tendências presentes no pensamento de von Hardenberg, salientando novamente o caráter plural de seus fragmentos. Outro aspecto da Filosofia da crise ecológica que nos conduz a pensar sobre Novalis é o terceiro capítulo, em que ele discute o problema da motivação moral. Para Hösle, devemos reconhecer valore próprio à natureza, e também direitos. Com isso, ele está aplicando a concepção de Hans Jonas, segundo a qual devemos levar em conta direitos das gerações vindouras. Os que virão possuem direito à vida, e a natureza não deve ser apenas um obstáculo ao dever moral, um não-eu fichteano, mas ela mesma é dotada de direitos, devendo ser tratada com respeito e com responsabilidade. Nesse contexto, Hösle afirma que a motivação moral é de suma importância, e o sentimento de respeito pela lei moral e a ideia de dever, por si sós, não conseguem motivar o suficiente. Outros 
valores devem ser introduzidos, inclusive uma dose saudável de interesse pessoal, de egoísmo, para se refletir sobre a preservação de si mesmo que está em jogo, quando se trata de proteger a natureza. Uma vez que se é parte do mundo natural, proteger o cosmos é também se manter vivo (HÖSLE, 1991, pp. 69-92). No que diz respeito a uma maior motivação moral para se proteger o meio ambiente, Novalis pode contribuir, com a ideia de que o amor pela natureza permite a sua moralização, e ele deve ser incentivado pelo estado (III, 1537, 227). Essa articulação entre amor e natureza não é mero sentimentalismo no caso de Novalis pois, para ele, amor é a meta da trajetória humana, o fim último (Endzweck) da história mundial (III, 1510, 220).

$\mathrm{O}$ mundo atual se encontra em crise em vários sentidos - crise ecológica, crise política, crise de identidade pessoal (agravada pelo uso das redes sociais - ou, melhor, por como somos usados pelas redes sociais). A reflexão filosófica e o retorno aos a pensadores não atuais não serve apenas para saudosismo ou escapismo do tempo atual e de suas mazelas (o que é válido, pois somos apenas humanos e precisamos de escapismo também, para lidar com as dificuldades da vida). Essas atitudes, de refletir filosoficamente e de recorrer à sabedoria dos clássicos, nos permitem recursos e ferramentas para lidar melhor com quem somos e com o nosso projeto enquanto humanidade.

Novalis, apesar de sua escrita em fragmentos, conseguiu uma reflexão poderosa sobre como nos relacionamos com a natureza e nos confere a possibilidade de nos tornarmos mais atenciosos com ela, reconhecendo sua grandeza e nos pensando como parte dela. Hösle, por sua vez, embora provavelmente não concorde com o idealismo mágico de Novalis, oferece base conceitual e também soluções práticas para o problema da crise ecológica, que se acentua não a cada ano, mas a cada mês.

\section{REFERÊNCIAS}

ALBERT, H. "Hösles Sprung in den objektiven Idealismus: Über die Verwirrungen eines ganz gewöhnlichen Genies". Zeitschrift für allgemeine Wissenschaftstheorie, v. 20, n. 1 (1989): 124-131. Disponivel em: . Acesso em: 29 Out. 2020.

ASSUMPÇÃO, G. "A pintura abstrata e Schelling: atravessar a "pele da natureza" ". Princípios (UFRN), v. 24, n. 45, (2017): 59-79. Disponivel em: . Acesso em: 29 Out. 2020.

ASSUMPÇÃO, G. "Crítica do juizo teleológico e organismo em Kant e Schelling". Doispontos: Curitiba, São Carlos, vol. 2, n. 02 (2015): 123-135. Disponível em: . Acesso em: 29 Out. 2020.

ASSUMPÇÃO, G.; VELIQ, F. "Vittorio Hösle, um filósofo para o século XXI". In: HÖSLE, V. Filosofia da crise ecológica. Conferências moscovitas. Trad. ASSUNÇÃO, G. São Paulo: LiberArs, 2019, pp. 9-22.

BEISER, F. German Idealism. The struggle against subjectivism. 1781-1801. Cambridge, MA/ London: Harvard University Press, 2002.

BEISER, F. The Romantic Imperative: The Concept of Early German Romanticism. Cambridge, MA/London: Harvard University Press, 2003.

CORÔA, P. P. da C. "Projeto Crítico e o Romantismo de Novalis". Studia Kantiana n. 17, v. 2 (2019): 43-62. Disponível em: . Acesso em: 28 Out. 2020.

DURNER, M.; JANTZEN, J.; MOISO, F. (Hrsg.) Friedrich Wilhelm Joseph Schelling Historischkritische Ausgabe. Ergängzungsband: Wissenschafthistorischer Bericht zu Schellings Naturphilosophische Schriften 1797-1800. Stuttgart: Frommann-Holzboog, 1994.

FRANK, M. Einführung in die frühromantische Ästhetik. Vorlesungen. Frankfurt am Main: Suhrkamp, 1989.

FRIEDELL, E. Novalis als Philosoph. München: Verlagsanstalt F. Bruckmann A.-G., 1904. Disponivel em: . Acesso em: 28 Out. 2020.

GONÇALVES, M. "Schelling: filósofo da natureza ou cientista da imanência?". In: PUENTE, F. R.; VIEIRA, L. A. (Orgs.). As filosofias de Schelling. Belo Horizonte: Editora UFMG, 2005, pp. 71-90. 
HELDT, M. B. “O idealismo objetivo de Vittorio Hösle". Cognitio-Estudos: revista eletrônica de filosofia, v. 13, n. 1 (2016): 77-92. Disponível em: . Acesso em: 28 Out 2020.

HÖSLE, V. Foundational Issues of Objective Idealism. In: HÖSLE, V. Objective Idealism, Ethics and Politics. South Bend: St. Augustine's Press, 1998, pp. 1-40.

HÖSLE, V. Philosophie der ökologischen Krise. Moskauer Vorträge. München: Verlag C. H. Beck, 1991.

KOYRÉ, A. Do mundo fechado ao Universo Infinito. Trad. D. M. Garschagen. $4^{\mathrm{a}}$ ed. Rio de Janeiro: Forense Universitária, 2006.

LOSSO, E.G. B. "História, analogia e natureza em Novalis". Pandaemonium Germanicum, v. 23, n. 41 (2020): 125-152. Disponivel em: . Acesso em: 28 Out. 2020.

MATIJEVIĆ, D. "Hösleovo povećalo: modeliranje ekološke budućnosti ljudskoga društva". Društvena istraživanja: Journal for General Social Issues, v. 24, n. 1 (2015): 111-131. Disponivel em: . Acesso em: 28 Out. 2020.

MULLER, M.L.. Vittorio Hösle - Uma Filosofia da Crise Ecológica. Cadernos de História e Filosofia da Ciência, v. 6., n. 2 (1996): 1-53.

NASSAR, D. The Romantic Absolute. Being and Knowing in Early German Romantic Philosophy, 1795-1804. Chicago/London: The University of Chicago Press, 2014.

NOVALIS, Gesammelte Werke. Dritter Band: Fragmente II. Hrsg. Carl Seelig. Heerliberg/Zürich: Bühl-Verlag, 1946. Disponivel em: . Acesso em: 28 Out. 2020.

NOVALIS. Gesammelte Werke. Vierter Band: Fragmente III. Hrsg. Carl Seelig. Heerliberg/Zürich: Bühl-Verlag, 1946. Disponivel em: https://archive.org/details/in.ernet.dli.2015.185723/ page/n1/mode/2up. Acesso em: 30 Out. 2020.

NOVALIS.Gesammelte Werke. Zweiter Band: Fragmente I. Hrsg. Carl Seelig. Heerliberg/Zürich: Bühl-Verlag, 1945. Disponivel em: . Acesso em: 28 Out. 2020.

OLIVEIRA, M. A. de. "Filosofia da natureza e idealismo objetivo: uma leitura da postura sistemática de Hegel segundo D. Wandschneider e V. Hösle”. Filosofia Unisinos, v. 7, n. 1 (2006): 40-61. Disponivel em: . Acesso em: 28 Out. 2020.

SCHELL, M. Poética do Romantismo - Novalis e o fragmento literário. São Paulo: Edusp, 2010.

SCHELLING, F. W. J. Erster Entwurf eines Systems der Naturphilosophie (1799). In: SCHELLING, F. W. J. Friedrich Wilhelm Joseph Schelling Historisch-Kritische Ausgabe. Reihe I: Werke 7. Herausgegeben von Wilhelm Jacobs und Paul Ziche. Stuttgart: Frommann-Holzboog, 2001.

SCHLEGEL, A. Vorlesungen über schöne Literatur und Kunst. Erster Teil (1801-1802): die Kunstlehre. Heilbronn. Verlag von Gebr. Henninger, 1884. Disponível em: . Acesso em: 28 Out 2020.

SEEL, M. Eine Ästhetik der Natur. Frankfurt: Suhrkamp, 1996.

SELIGMANN-SILVA, M. "Friedrich Schlegel e Novalis: Poesia e Filosofia". Revista Terceira Margem, v. 10, n. 15 (2006): 95-111. Disponivel em: . Acesso em: 28 Out. 2020.

SOUZA, L. C. S. de. "A metafísica enquanto teoria transcendental absoluta em Joseph Maréchal e Vittorio Hösle”. Síntese - Revista de Filosofia, v. 33, n. 107 (2006): 393-412. Disponível em: . Acesso em: 28 Out. 2020.

UERLINGS, H. Friedrich von Hardenberg, genannt Novalis. Werk und Forschung. Stuttgart: J. B. Metzler, 1991.

VAN DER VAL, K., Die Wirklichkeit aus neuer Sicht. Für eine andere Naturphilosophie. Wiesbaden, Springer VS, 2017.

\section{Notas}

1 "Die Natur addiert, subtrahiert, multipliziert, potenziert etc. Unaufhorlich. Die angewandten mathematischen Wissenschaften zeigen uns die Natur als Mathematiker ". Todas as traduções são de nossa responsabilidade. Essa noção encontrará eco na Doutrina da arte de August Schlegel (1884, p. 136s.) e, também, no pensamento de Schelling (2001, p. 29), que defenderão haver uma inteligência aconsciente na natureza, que se expressa em represas de castores, colmeias, "mentalidade de enxame", padrões geométricos em minerais e em folhas, etc. Sobre a filosofia da natureza dos românticos e suas influências cientificas, cf. AUTOR, 2015, 2017; BEISER, 2002, p. 483-550; 2003, p. 82-87; DURNER et al, 1994; FRIEDELL, 1904, p. 39s; GONÇALVES, 2005; LEMOS, 2019; UERLINGS, 1991. 
2 "Die Poesie ist das echte absolut Reele. Dies ist der Kern meiner Philosphie. Je poetischer, je wahrer". Ver também III, 807, 22 e III, 806, 22.

3 Novalis não aceita plenamente a filosofia da natureza de Schelling, e o ponto fraco de sua filosofia da natureza, comparada com a de Schelling, é não possuir um conceito de natureza como produtividade, uma das maiores intuições schellinguianas. Um ponto forte de Novalis é seu conhecimento mais sofisticado da matemática.

4 "Alles ist Zauberei oder nichts. Vernünftmäsigkeit der Zauberei".

5 "Die Natur ist Feidin ewiger Besitzungen".

6 "Idealisierung des Realism und Realisierung des Idealism führt auf Wahrheit. Eines arbeitet für den andern und so indirekt für sich. Der Idealist muss, um direkt für den Idealism zu arbeiten, den Realism zu beweisen suchen und umgekehrt. Der Beweis des Realism ist der Idealism und umgekehrt".

7 As conferências de Hösle sobre ecologia foram dadas em um contexto de visita à ex-URSS, com uma intenção de conciliar Leste e Oeste, tendo como instrumentos mediadores a Alemanha e a filosofia. O filósofo nota que tanto o capitalismo quanto o socialismo empreenderam danos ao meio-ambiente, devido às corridas armamentista e espacial, ao desenvolvimento de arsenais nucleares, à ênfase no setor industrial, e busca uma forma de economia que concilie aspectos positivos do capitalismo e do socialismo, no que tange ao cuidado com o meio ambiente, uma espécie de economia social de mercado (HÖSLE, 1991, pp. 16-42; 96-120), defendendo que ecologia e economia não são incompativeis, mas que uma pode se beneficiar da outra, a partir das noções de parcimônia no uso de recursos e interesse (Cf. MULLER, 1996).

8 Essa interpretação de Hösle lembra as reflexões de Alexandre Koyré (2006) sobre o "mundo fechado" dos antigos, em oposição ao "mundo aberto" dos modernos, o que só foi possível devido à matematização do mundo e à ideia de infinito. 